\title{
Antiplatelet agents, carotid endarterectomy, and perioperative complications
}

\author{
Bradford B. Worrall, M.D., AND Karen C. Johnston, M.D., M.Sc. \\ Department of Neurology, University of Virginia, Charlottesville, Virginia
}

\begin{abstract}
Neurosurgeons are frequently involved in chosing an antiplatelet therapy for their patients in the perioperative period. New data obtained from the Aspirin and Carotid Endarterectomy (ACE) Trial suggest that low-dose aspirin is superior to high-dose aspirin therapy in reducing rates of perioperative stroke and death. The ACE-related data are reviewed, and the authors provide an update on current Food and Drug Administration-approved antiplatelet therapies for secondary stroke prevention, as well as a summary of antiplatelet therapies being developed.
\end{abstract}

\section{KEY WORDS • antiplatelet agent • carotid endarterectomy • perioperative complication}

Neurosurgeons frequently play a key role in the choice of stroke-prevention therapy. Their role is paramount in patients undergoing evaluation for CEA. Antiplatelet therapy is the mainstay in the prevention of secondary stroke in most patients in whom a cardioembolic source is not found. Therefore, in addition to selecting appropriate candidates to undergo CEA, neurosurgeons may need to choose medical therapy that reduces the risks of perioperative stroke and death. Two recent developments in the treatment of cerebrovascular disease may directly affect such choices. First, new prospective, randomized data on aspirin dosing obtained in in a CEA populations are now available. Second, physicians now have more choices for the use of antiplatelet therapy in the prevention of stroke that include several different mechanisms of action.

\section{ANTIPLATELET THERAPIES}

Platelet adhesion is thought to play an integral role in the development of symptomatic cerebrovascular disease. ${ }^{28}$ Figure 1 provides an illustration of the sites of action for commonly used antiplatelet agents. The mechanism of aspirin's antiplatelet activity has been well characterized and is thought to work predominantly through its inhibition of cyclooxygenase. Exposure of collagen during CEA has been suggested as a strong stimulus to platelet aggregation. ${ }^{24}$ This has led to an interest in examining the use of aspirin in the perioperative period.

Abbreviations used in this paper: $\mathrm{CEA}=$ carotid endarterectomy; $\mathrm{FDA}=$ Food and Drug Administration; $\mathrm{MI}=$ myocardial infarction .

\section{Aspirin Therapy}

Aspirin is the only antiplatelet drug to be well studied in populations of patients undergoing CEA. Based on a subgroup analysis of the North American Symptomatic Carotid Endarterectomy Trial studies, ${ }^{2,30}$ a differential effect of high-compared with low-dose aspirin on perioperative stroke and death was suggested. This was in part supported by earlier positive studies in which patients received high-dose aspirin $(>1 \mathrm{~g})$ post-CEA ${ }^{6,26}$ and one negative study in which very low-dose aspirin $(50 \mathrm{mg})$ was used. ${ }^{8}$ Analysis of other data has indicated that lowdose aspirin $(75 \mathrm{mg})$ was effective in preventing recurrent stroke after CEA.21

The Aspirin and Carotid Endarterectomy (ACE) Trial ${ }^{30}$ was a prospective, randomized double-blinded, controlled trial of low-dose (81-mg or 325-mg) and high-dose (650mg or 1300-mg) aspirin therapy in patients undergoing CEA. This international study enrolled 828 patients scheduled for CEA with both symptomatic $(46 \%)$ and asymptomatic $(54 \%)$ carotid artery stenosis that was greater than or equal to $60 \%$. All participating surgeons reported 30-day stroke and death rates of up to $6 \%$. Patients were randomized to one of four dosage groups approximately 2 days prior to surgery. The patients were followed for 3 months postoperatively, and a combined outcome of stroke, MI, and death was compared between the lower-dosage tiers $(81 \mathrm{mg}$ or $325 \mathrm{mg}$ ) and the higherdosage tiers $(650 \mathrm{mg}$ or $1300 \mathrm{mg}$ ) in a prespecified primary analysis. Baseline characteristics including type of surgeon and technique used were similar among the four groups. In the lower-dosage group lower postoperative 


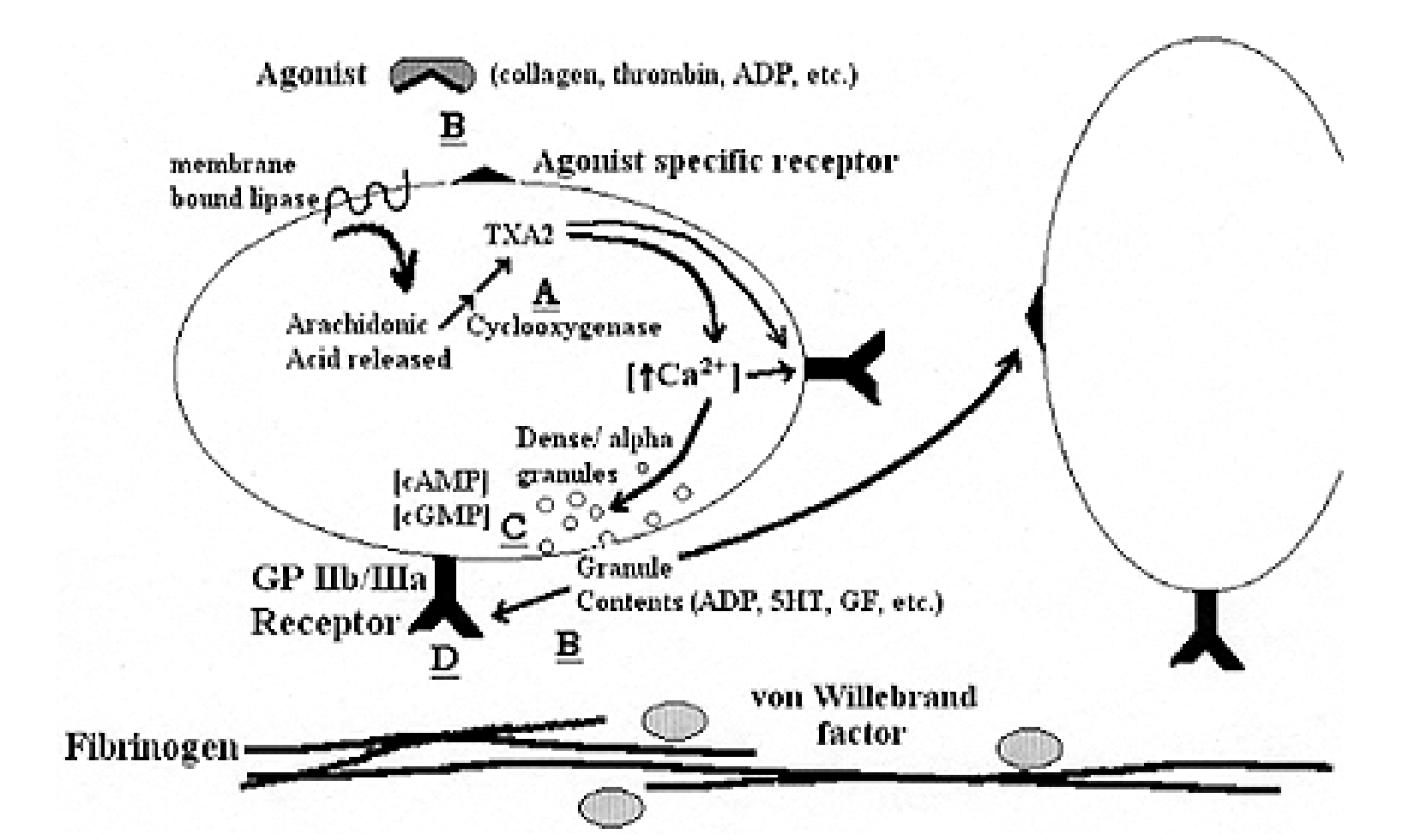

Fig. 1. Schematic diagram depicting one of the major pathways for platelet aggregation. An agonist such as collagen, thrombin, or adenosine diphosphate (ADP) binds to a specific receptor on the surface of the platelet. This binding initiates several processes. One is release of arachidonic acid by a membrane-bound lipase. Via a multistep process, arachidonic acid is converted to thromboxane A2 (TXA2). One of these steps is mediated by cyclooxygenase. Thromboxane A2 increases intracellular calcium $(\mathrm{Ca} 2+)$, which promotes fusion of dense and alpha granules with the platelet membranes releasing their contents (including ADP, 5-hydroxytryptamine [5HT], and growth factor [GF]). These substances result in conformational change of the glycoprotein IIbIIIa receptor-activating binding sites for specific peptide sequences found on fibrinogen and von Willebrand factor. Multiple platelets bind to the same fibrinogen molecule, forming a molecular bridge that results in aggregation.

Granule release is influenced by the intracellular concentrations of cyclic adenosine (cAMP) and cyclic guanine monophosphate (cGMP). Agonists, particularly collagen and thrombin may have direct effects on granule release, and both thromboxane $\mathrm{A} 2$ and intracellular $\mathrm{Ca} 2+$ concentration can have direct effects on IIbIIIa receptor exposure promoting aggregation. A: The site of aspirin's blockade of cylcooxygenase. B: The sites of action of the thienopyridines (ticlopidine and clopidogrel). C: The site of action of dipyridamole by increasing intracellular cyclic nucleotides. D: The receptor that is blocked by IIbIIIa antagonists.

rates of stroke, MI, and death were demonstrated as compared with those in the high-dosage group at both 30 days (5.4\% and $7.0 \%$, respectively; $\mathrm{p}=0.07)$ and 3 months $(6.2 \%$ and $8.4 \%$, respectively; $\mathrm{p}=0.03)$. In a prespecified secondary "efficacy analysis" attempting to correct for the lack of a wash-out period similar results were found.

In 1998, the FDA modified the language of the professional labeling of aspirin for the prevention of stroke, recommending that range of 50 to $325 \mathrm{mg}$ be used for the prevention of stroke and transient ischemic attacks. ${ }^{14}$ The results of the ACE trial were not available at the time of the labeling review, and therefore the labeling continues to recommend that administration of 80 to $1300 \mathrm{mg}$ of aspirin be initiated "preoperatively and continued indefinitely" in patients undergoing CEA. A new metaanalysis that included many of these same studies reviewed by the FDA found a risk reduction of $15 \%$ across all dose levels. ${ }^{18}$

In a recent study in patients undergoing CEA the authors did not find perioperative aspirin use to be an independent risk factor for postoperative hematoma formation. ${ }^{27}$ However, with only 29 cases of postoperative hematomas in the study population, the risk of a Type II error is great. Although not studied in a CEA population, new safety data have been reported on the risk of major complications related to various agents used in the prevention of secondary stroke; the authors found a rate of 3.5 major complications and 0.2 deaths per 100 person years for patients undergoing aspirin therapy. ${ }^{25}$ These data serve as reminders that, although aspirin is safe and effective, complications including hemorrhage can occur in aspirin-treated patients.

\section{Other Agents}

None of the newer antiplatelet agent has been specifically studied in patients requiring CEA. However, because patients being evaluated for a possible CEA may be receiving these newer agents, a brief review of available data is warranted.

Ticlopidine and clopidogrel are FDA-approved agents used in the prevention of secondary stroke. These chemically related compounds are both thienopyridines and inhibit platelet aggregation by similar mechanisms. 
Ticlopidine ${ }^{15,17}$ has been shown to be superior to aspirin in reducing recurrent stroke, but its clinical use has been limited because of its safety profile. Recently, an additional concern about potentially fatal thrombotic thombocytopenic purpura has been identified., ${ }^{3,5,10}$ Early recognition and treatment with plasmapheresis has been shown to improve survival..$^{5}$ Although the exact risk is unknown, an estimate based on available data is one per 2000 cases treated. ${ }^{31}$ The risks of this and other triclopidine use-related complications need to be weighed against potential benefits.

Clopidogrel has been shown to reduce MI, stroke, and vascular disease-related death in patients who have suffered recent stroke, recent MI, or in whom there is established peripheral arterial disease. ${ }^{9}$ Since the drug received FDA approval, the manufacturer estimates that 1.5 million people have been exposed to clopidogrel (D. Kargman and C. Sekaran, Sanofi-Synthelabo Inc., personal communication). Continued postmarketing surveillance for adverse events including blood dyscrasia is ongoing.

The recent FDA approval of combination extendedrelease dipyridamole and very low-dose aspirin has added a fourth agent to our antiplatelet armamentarium. ${ }^{13}$ In a very large clinical trial, this combination therapy was shown to have a statistically significant effect on reducing the risk of recurrent stroke, but it did not affect the rate of MI or death. ${ }^{11}$ There is some conflicting data on the use of regular dipyridamole in patients undergoing CEA. ${ }^{12,16}$ No additional studies of this combination or the newer extended-release formulation in CEA patients were found in our search of the literature.

Other antiplatelet agents such as IIbIIIa antagonist therapy can be potentially used for the prevention of stroke in both those who have already suffered stroke and those undergoing CEA. However, to date, no published studies conducted in humans were found to support the use of these in either of the aforementioned populations. Concerns over severe thrombocytopenia ${ }^{22}$ and marked increased bleeding risk $^{7}$ have been raised regarding this class of agents and may limit their use in a CEA population. Clinical trials in which investigators are examining the safety and efficacy of oral IIbIIIa antagonists in stroke patients are ongoing.

Combination therapies also hold promise as potentially superior aggregation blockades that may lead to our improved ability to prevent stroke. The thienopyridines have been studied in conjunction with aspirin in other vessel-related procedures such as placement of coronary stents ${ }^{19,23}$ and have been widely used in these populations because of the proven ${ }^{20}$ or perceived ${ }^{29}$ superior antiaggregant effects of combination therapy over aspirin alone. No combination therapies other than dipyridamole and aspirin have been reported in patients undergoing CEA.

\section{CONCLUSIONS}

The recently published ACE data suggest that in patients undergoing CEA, reduced perioperative stroke and death rates occur when receiving low-dose aspirin $(<325$ $\mathrm{mg})$ as compared with high-dose aspirin treatment $(>650$ $\mathrm{mg}$ ). Although these remain the only randomized, blinded, controlled data obtained in the perioperative period in patients undergoing antiplatelet therapy in CEA patients, there are now several other FDA approved antiplatelet agents. Surgeons need to be aware of the potential risks and benefits of each of the antiplatelet agents as they relate to CEA and secondary stroke prevention. Additional research is needed to identify the optimum secondary stroke prevention therapy in the perioperative period and beyond.

\section{ADDENDUM}

Since this work was submitted, two recent articles have been published that provide additional information on antiplatelet therapy. A randomized, double-blind, placebocontrolled dose-escalation study of abciximab, a IIbIIIa antagonist, in 74 ischemic stroke patients has been recently published. ${ }^{1}$ The patients were treated with placebo or one of four doses of abciximab. It was suggested that the $0.25-\mathrm{mg} / \mathrm{kg}$ bolus and 12-hour infusion regimen be submitted for further safety and efficacy evaluation.

An early release of an article by Bennett, et al., ${ }^{4}$ has been made available on the New England Journal of Medicine Web page (http://www.nejm.org/content/bennett/1. asp.) The authors describe 11 cases of thrombotic thrombocytopenic purpura in patients who were receiving or had recently received clopidogrel, out of an estimated three million individuals exposed to it. They recommended that physicians be aware of the possibility of thrombotic thrombocytopenic purpura among patients receiving clopidogrel.

\section{References}

1. The Abcixicab in Ischemic Stroke Investigators: Abcixicab in acute ischemic stroke: a randomized, double-blind, palcebocontrolled, dose-escalation study. Stroke 31:601-609, 2000

2. Barnett HJ, Taylor DW, Eliasziw M, et al: Benefit of carotid endarterectomy in patients with symptomatic moderate or severe stenosis. North American Symptomatic Carotid Endarterectomy Trial Collaborators. N Engl J Med 339:1415-1425, 1998

3. Bennett CL, Davidson CJ, Raisch DW, et al: Thrombotic thrombocytopenic purpura associated with ticlopidine in the setting of coronary artery stents and stroke prevention. Arch Intern Med 159:2524-8, 1999

4. Bennett CL, Connors JM, Carwile JM, et al: Thrombotic thrombocytopenic purpura associated with clopidogrel. N Engl J Med (In press, 2000)

5. Bennett CL, Weinberg PD, Rozenberg-Ben-Dror K, et al: Thrombotic thrombocytopenic purpura associated with ticlopidine. A review of 60 cases. Ann Intern Med 128:541-544, 1998

6. Bischof G, Pratschner T, Kail M, et al: Anticoagulants, antiaggregants or nothing following carotid endarterectomy? Eur J Vasc Surg 7:364-369, 1993

7. Blankenship JC: Bleeding complications of glycoprotein IIbIIIa receptor inhibitors. Am Heart J 138:287-296, 1999

8. Boysen G, Sorensen PS, Juhler M, et al: Danish very-low-dose aspirin after carotid endarterectomy trial. Stroke 19: 1211-1215, 1988

9. CAPRIE Steering Committee: A randomised, blinded, trial of clopidogrel versus aspirin in patients at risk of ischaemic events (CAPRIE). Lancet 348:1329-1239, 1996

10. Chen DK, Kim JS, Sutton DMC: Thrombotic Thrombocytopenic Purpura associated with ticlopidine use: a report of 3 cases and review of the literature. Arch Intern Med 159: 311-314, 1999 
11. Diener HC, Cunha L, Forbes C, et al: European Stroke Prevention Study. 2. Dipyridamole and acetylsalicylic acid in the secondary prevention of stroke. J Neurol Sci 143:1-13, 1996

12. Findlay JM, Lougheed WM, Gentili F, et al: Effect of perioperative platelet inhibition on postcarotid endarterectomy mural thrombus formation. Results of a prospective randomized controlled trial using aspirin and dipyridamole in humans. J Neurosurg 63:693-698, 1985

13. Food and Drug Administration: Aggrenox (Dipyridamole/aspirin) capsule. FDA's Report on New Health Care Products Approved in 1999. FDA Talk Paper, January 18, 2000.

14. Food and Drug Administration: Internal analgesic, antipyretic, and antirheumatic drug products for over-the-counter human use; final rule for professional labeling of aspirin, buffered aspirin, and aspirin in combination with antacid drug products. Fed Register 63:56802-56819, 1998

15. Gent M, Blakely JA, Easton JD, et al: The Canadian American ticlopidine study (CATS) in thromboembolic stroke. Lancet 1: 1215-1220, 1989

16. Harker LA, Bernstein EF, Dilley RB: Failure of aspirin plus dipyridamole to prevent restenosis after carotid endarterectomy. Ann Intern Med 116:731-736, 1992

17. Hass WK, Easton JD, Adams HP, et al: A randomized trial comparing ticlopidine hydrochloride with aspirin for the prevention of stroke in high-risk patients. N Eng J Med 321: 501-507, 1989

18. Johnson ES, Lanes SF,Wentworth CE III, et al: A metaregression analysis of the dose-response effect of apsirin on stroke. Arch Intern Med 159:1248-1253, 1999

19. Leon MB, Baim DS, Popma JJ, et al: A clinical trial comparing three antithrombotic-drug regimens after coronary-artery stenting. Stent Anticoagulation Restenosis Study Investigators. N Engl J Med 339:1665-1671, 1998

20. Leon MB, Popma JJ, Mintz GS, et al: An overview of US coronary stent trials. Semin Interv Cardiol 1:247-254, 1996

21. Lindblad B, Persson NH, Takolander R, et al: Does low-dose acetylsalicylic acid prevent stroke after carotid surgery? A double-blind, placebo-controlled randomized trial. Stroke 24: 1125-1128, 1993

22. Madan M, Berkowitz SD: Understanding thrombocytopenia and antigenicity with glycoprotein IIb-IIIa inhibitors. Am Heart J 138:317-326, 1999

23. Muller C, Buttner HJ, Petersen J, et al: A randomized comparison of clopidogrel and aspirin versus ticlopidine and aspirin after the placement of coronary-artery stents. Circulation 101: 590-593, 2000

24. O'Brien JR, Etherington MD: How much aspirin? Thrombosis Haemostasis 64:486, 1990 (Letter)

25. Petty GW, Brown RD Jr, Whisnant JP, et al: Frequency of major complications of aspirin, warfarin, and intravenous heparin for secondary stroke prevention: a population based study. Ann Intern Med 130:14-22, 1999

26. Pratschner T, Kretschmer G, Prager M, et al: Antiplatelet therapy following carotid bifurcation endarterectomy. Evaluation of a controlled clinical trial. Prognostic significance of histologic plaque examination on behalf of survival. Eur J Vasc Surg 4:285-289, 1990

27. Self DD, Bryson GL, Sullivan PJ: Risk factors for post-carotid endarterectomy hematoma formation. Can J Anaesth 46: 635-640, 19

28. Smith NM, Pathansali R, Bath PM: Platelets and stroke. Vasc Med 4:165-172, 1999

29. Steinhubl SR, Topol EJ: Clopidogrel with aspirin is the optimal antiplatelet regimen for intracoronary stenting. J Thromb Thrombolysis 7:227-231, 1999

30. Taylor DW, Barnett HJ, Haynes RB, et al: Low-dose and highdose acetylsalicylic acid for patients undergoing carotid endarterectomy: a randomized controlled trial. ASA and Carotid Endarterectomy (ACE) Trial Collaborators. Lancet 1999 353: 2179-2184, 1999

31. Worrall BB, Johnston KC: Antiplatelet therapy in secondary stroke prevention. Curr Atherosclerosis Rep 2: 104-109, 2000

Manuscript received March 13, 2000.

Accepted in final form April 20, 2000.

Dr. Worrall is supported in part by a grant from the American Academy of Neurology Clinical Research Training Fellowship.

Address reprint requests to: Bradford B. Worrall, M.D., University of Virginia Health System, Department of Neurology \#800394. Charlottesville, Virginia 22908. email: bbw9r@virginia.edu. 